\title{
Psychological Motivations of Students for Book Borrowing in Libraries of Higher Vocational Colleges from the Perspective of "Three Comprehensive Education"
}

\author{
https://doi.org/10.3991/ijet.v16i08.22125 \\ Rong Yan \\ Yangling Vocational and Technical College, Xianyang, China \\ zoesnow@hotmail.com
}

\begin{abstract}
The innovative "three comprehensive education" model can mobilize the initiatives of students in higher vocational colleges, whose book borrowing behaviors are affected by "three comprehensive education". This paper mainly studies the psychological motivations of students for book borrowing in libraries of higher vocational colleges from the perspective of "three comprehensive education". Firstly, the psychological motivations for book borrowing were analyzed in details under the mechanism of "three comprehensive education". Then, a dataset was created from the mass data on book borrowing and students. The relevant features were compressed as model inputs, aiming to improve model performance and reduce storage cost. Finally, a perception model was constructed to analyze the psychological motivations of students for book borrowing, and used to solve the five-class classification problem based on the directed acyclic graph. Experimental results prove the scientific of the psychological pattern analysis and the effectiveness of the proposed model. The research results provide a theoretical and practical reference for the effect analysis of "three comprehensive education".
\end{abstract}

Keywords - Three comprehensive education; higher vocational college; book borrowing; psychological pattern analysis

\section{Introduction}

In 2017, the State Council and the Central Committee of the Communist Party of China jointly issued the Opinions on Strengthening and Improving the Ideological and Political Work in Colleges and Universities under the New Situation, which mentioned that we must "adhere to whole-staff education, whole-process education and all-round education" or "three comprehensive education" for short. The "three comprehensive education" requires higher vocational colleges to integrate moral education resources and enhance the effectiveness of moral education among higher vocational college students [1-5]. The innovative "three comprehensive education" model can help mobilize the initiatives of higher vocational college students to conduct self-management, self- 
education and self-service [6-8], and students' book borrowing behaviours due to their interdisciplinary learning interests are just the manifestation of the "reading, culture and service-based education" mechanism in the "three comprehensive education" [9-14]. Therefore, studying students' psychological motivations for book borrowing in libraries of higher vocational colleges from the perspective of "three comprehensive education" is of great significance to transitioning the moral education operating mechanism in colleges from theory to practice.

In order to help students find the books they desire more efficiently, Yan et al. [15] conducted Apriori association rule mining on their book borrowing behaviour patterns, and implemented book recommendation and borrowing guidance based on the mining results. Through the algorithm optimization operation - jumping forward and backing fill, the mining efficiency of the algorithm was greatly improved. McKay et al. [16] started with revealing students' interdisciplinary learning interests and borrowing behaviour patterns, and then conducted quantitative analysis of the big data of book borrowing from the perspective of behavioural dynamics using the scaling law, constructed a student learning interest network based on the analysis results, and implemented book recommendation based on students' learning interest ratings. Feng et al. [17] conducted a statistical analysis of popular books, popular books on humanities and high borrowing rates in the libraries of higher vocational engineering colleges by grade and major, and the results showed that popular non-engineering books mainly include literature, English and computer teaching-aid books, supplemented by music books like musical instrument tutorials and popular readings represented by social science books. Zhang et al. [18] compared the advantages and disadvantages of common library book recommendation technologies and conducted the analysis of students' psychology and behaviours of borrowing from the perspectives of borrowing time series and student characteristics. It performed cluster analysis of students' borrowing behaviours with borrowing frequency as the main reference using the software IBM SPSS Modeler and implemented book recommendation based on the correlation analysis results of different books. Tang [19] used the K-means algorithm based on matrix data to cluster the students borrowing books by the number of books borrowed, summarized the distribution of age, gender and borrowing and returning time in each category of students, and at last drew the conclusion that students borrow books mostly for the purpose of helping their major courses and English learning and improving their literary and artistic accomplishments.

So far, the research on the "three comprehensive education" has mostly focused on its connotation, value and characteristics and the construction of cultivation strategies, and no research has conducted any empirical analysis of its implementation effect [20, 21]. To this end, this paper studied students' psychological motivations for borrowing in libraries of higher vocational colleges from the perspective of "three comprehensive education", which verified the role of the "three comprehensive education" moral education model in mobilizing higher vocational college students' initiatives for self-management, self-education, and self-service. Section 2 of this paper first analyses students' psychological motivations for book borrowing from the perspective of "three comprehensive education", and gives the specific analysis process of students' learning interests across disciplines and psychological motivations for book borrowing. Then, 
regarding the data sample set formed from the massive borrowing information and data of students, Section 3 optimizes the model input based on feature dimension compression to improve the model performance and reduce the storage cost. Section 4 constructs a perception model for students' psychological motivations for book borrowing, and solves the five-class classification problem of the perception model based on the directed acyclic graph. The experimental results prove the scientificity of the psychological pattern analysis method used and the effectiveness of the proposed model.

\section{Analysis of Students' Psychological Motivations for Book Borrowing from the Perspective of "Three Comprehensive Education"}



Fig. 1. Flow chart of cross-discipline learning interest analysis from the perspective of "three comprehensive education"

The book borrowing system in a college is a complex one, whose overall characteristics are manifested by the behaviours of students. Each student has his own major and the books he or she borrows may fall within different disciplines and subjects. If a student changes his or her borrowing behaviour and even develops learning interests across disciplines, it can be regarded that this student's psychological pattern of book borrowing has changed under the influence of the "three comprehensive education" moral education model. This paper believes that, from the statistical point of view, if 
students majored in a certain discipline borrow a large number of books that belong to other disciplines, then there must be certain knowledge connections between these disciplines, and such potential knowledge connections can be used to characterize the changes in students' learning interests and psychological motivations for book borrowing from the perspective of "three comprehensive education".

Students' book borrowing records include borrowing and returning records. For each book, the record contains basic information such as its title, classification number and discipline category. From the borrowing and returning records, how long a student borrows a book can also be derived. To analyse and dig out students' learning interests, the basic information of students and books and the information of book borrowing must be incorporated into one information sheet. The purpose of the "three comprehensive education" reform is to achieve the development and improvement of ideological and political work in higher vocational colleges under the new situation, and to promote the full implementation of the fundamental moral education. The effectiveness of this education model is subtle, and a single sample cannot be used as the only criterion for verification. During the implementation of the comprehensive reform model, massive amount of students' book borrowing information and data was analyzed, from which, the similarity analysis results regarding the psychological motivations for borrowing were obtained, with statistical significance. These analysis results can be used for research on identification of student learning interest groups and book association rule mining, and the conclusions from the effect analysis of "three comprehensive education" also have certain significance.

Based on the ideas of learning interest analysis and learning interest group identification, the analysis flow diagram for students' psychological motivations for book borrowing was constructed from the perspective of "three comprehensive education", as shown in Figure 2. The analysis process is divided into three stages: input optimization, psychological motivation and pattern perception and effect analysis of "three comprehensive education". The psychological pattern perception model proposed in this paper is to perceive the psychological motivations of students for book borrowing in higher vocational colleges under the guidance of the "three comprehensive education:" concept, so as to predict their psychological motivations for book borrowing. The judgment on a student' psychological motivation for book borrowing is the output result of the constructed model. Under the guidance of the "three comprehensive education" concept for higher vocational colleges, students' psychological motivations for book borrowing are classified into five types, namely learning assistance, professional research, casual pleasure, curiosity and speculation and rebellion. Therefore, the psychological pattern perception model is essentially to solve the five-class classification problem in supervised learning. In this paper, to reduce the dimensions of massive borrowing information and data, the model input was optimized using the genetic algorithm, and then the support vector machine algorithm was selected as the classification model algorithm for the psychological motivations of students for book borrowing in the libraries of higher vocational colleges from the perspective of "three comprehensive education". 


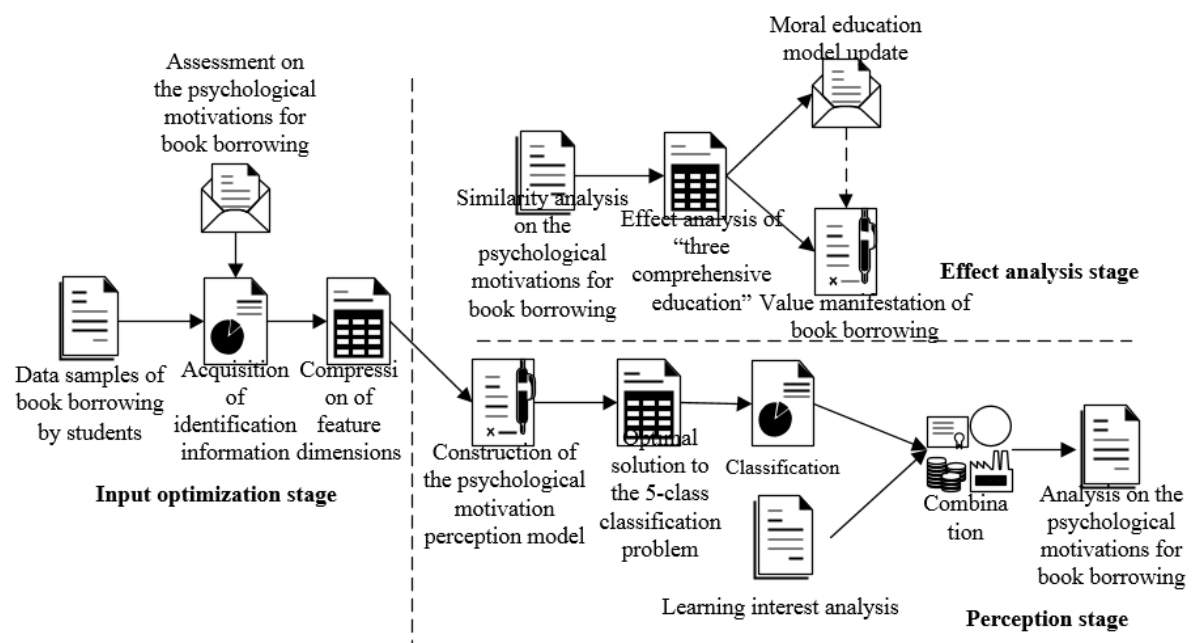

Fig. 2. Analysis flow chart for students' psychological motivations for book borrowing from the perspective of "three comprehensive education"

\section{Optimization of the Samples of Students' Book Borrowing Information and Data}

For the data sample set constructed from the massive borrowing information and data of students, the purposes of optimizing the model input based on feature dimension compression are to improve model performance and reduce storage costs. The reason that the genetic algorithm is used in this paper for feature dimension compression is that it can select the optimal feature combination from the multi-dimensional features of the massive borrowing information and data samples. It first calculates the fitness function based on the distance criterion to complete the iteration of the data samples with classification identifiers, and finally selects the most ideal feature combinations for accurate classification based on the roulette wheel selection strategy. Suppose that the $i$-th mean vector of students' borrowing data samples is represented by Formula (1):

$$
S_{i}=\frac{1}{N_{i}} \sum_{p=1}^{N_{i}} B_{p}^{i}
$$

where, $N_{i}$ is the number of samples corresponding to the $i$-th category. The total mean vector of the sample set is represented by Formula (2):

$$
S=\frac{1}{N} \sum_{p=1}^{N} B_{p}^{i}=\sum_{i=1}^{5} Q\left(\omega_{i}\right) S_{i}
$$

where, $Q\left(\omega_{i}\right)$ is the prior probability of students' borrowing data samples being classified into the $i$-th category. Then the scatter matrix between the samples of the same category can be expressed by Formula (3):

$$
M_{I}=\sum_{i=1}^{5} Q\left(\omega_{i}\right) \cdot \frac{1}{N_{i}} \sum_{p=1}^{N_{i}}\left(B_{p}^{i}-S_{i}\right)\left(B_{p}^{i}-S_{i}\right)^{T}
$$


The scatter matrix between the samples of different categories can be expressed by Formula (4):

$$
M_{O}=\sum_{i=1}^{5}\left[Q\left(\omega_{i}\right) \frac{1}{N_{i}} \sum_{p=1}^{N_{i}}\left(S_{i}-S\right)\left(S_{i}-S\right)^{T}\right]
$$

The fitness function in the model based on distance criterion is calculated by Formula (5):

$$
F I T=\frac{\operatorname{tr}\left(S_{O}\right)}{\operatorname{tr}\left(S_{I}\right)}
$$

To make the classification effect of the support vector machine better, the distances between samples of the same category must be minimized, and those between samples of different categories maximized. The fitness function equal to the inter-class to intraclass distance ratio can be used to measure the classification effect of the support vector machine - the larger the function value, the better the classification effect of the model. The roulette wheel selection strategy of roulette can be expressed by Formula (6):

$$
Q_{i}=\frac{\sum_{1}^{i} F I T_{i}}{\sum_{i=1}^{N} F I T_{i}}
$$

It can be seen from the formula that the ratio of the individual fitness value to the population fitness value is used as the selection criteria for the next generation of genetic population. The higher the fitness value, the higher the probability of being selected. Figure 3 shows the flow chart of the algorithm.

It takes several stages to prepare the training sample set of students' borrowing information and data. The first is to obtain the identification data. Since the proposed psychological pattern perception model in this paper is a 5-class classification model, identification data are needed to mark the sample data sets. The identifications are obtained based on the psychological test scores of book borrowing, and then combined with the identification data and the processed feature dimensions, the sample set of students' borrowing information and data is formed and according to the above feature selection method, the optimal feature dimension combination is selected and applied in the training of the support vector machine. 




Fig. 3. Flow chart of the genetic algorithm for input optimization

\section{Construction of the Perception Model for Students' Psychological Motivations for Book Borrowing}



Fig. 4. Principle of the binary classification of the support vector machine

Figure 4 is a schematic diagram of the principle of binary classification of the support vector machine. It can be seen that the purpose of the support vector machine is to seek a straight line or hyperplane to distinguish between two types of sample data based on spacing maximization. Let $B_{n}=\left\{b_{n}{ }_{n}, b^{2}{ }_{n}, \ldots, b^{M}{ }_{n}\right\}$ represent the feature dimension vector of a group of M-dimensional input data samples, and $l_{n}$ be the corresponding classification identifier, and then the data set composed of $\mathrm{N}$ groups of $\mathrm{M}$-dimensional input data samples can be expressed as $B=\left\{\left(B_{1}, l 1\right),\left(B_{2}, l_{2}\right), \ldots,\left(B_{N}, l_{N}\right)\right\}$. Suppose the weight vector is expressed as $\omega^{T}=\left\{\omega_{1}, \omega_{2}, \ldots, \omega_{M}\right\}$, and $\varepsilon$ denotes the bias term, then the linear 
hyperplane used for classification in the support vector machine can be expressed by Formula (7):

$$
H: \omega^{T} \cdot B+\varepsilon=0
$$

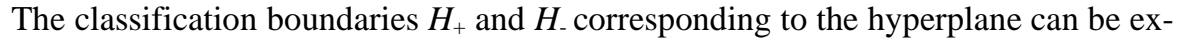
pressed by Formula (8):

$$
\left\{\begin{array}{c}
H_{+}: \omega^{T} B+\varepsilon \geq 1, l=1 \\
H_{-}: \omega^{T} B+\varepsilon \leq-1, l=-1
\end{array}\right.
$$

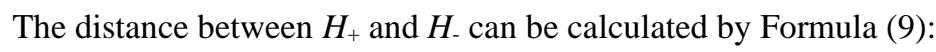

$$
d=\frac{2}{\|\omega\|} \quad \text { s.t. } l_{i}\left(\omega^{T} B_{i}+\varepsilon \geq 1\right), i=1,2, \cdots, N
$$

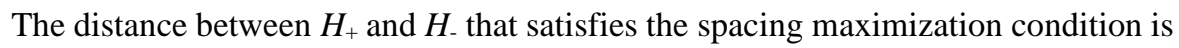
the objective function of the support vector machine:

$$
O F=\max _{\omega, \varepsilon} \frac{1}{\|\omega\|}=\min _{\omega, \varepsilon} \frac{1}{2}\|\omega\|^{2} \quad \text { s.t. } l_{i}\left(\omega^{T} B_{i}+\varepsilon \geq 1\right), i=1,2, \cdots, N
$$

Based on the convex optimization problem solving principle and the KKT condition, the optimal solution to Formula (10) is calculated, and the constrained objective function shown in Formula (10) is converted to the simplified unconstrained Lagrangian objective function shown in Formula (11):

$$
\begin{aligned}
& \min _{\alpha} \frac{1}{2} \sum_{i=1}^{N} \sum_{j=1}^{N} \alpha_{i} \alpha_{j} l_{i} l_{j}\left(B_{i} \cdot B_{j}\right)-\sum_{i=1}^{N} \alpha_{i} \\
& \text { s.t. } \sum_{i=1}^{N} \alpha_{i} l_{i}=0, \alpha_{i} \geq 0, i=1,2, \cdots, N
\end{aligned}
$$

where, $\alpha_{i}$ is a Lagrangian multiplier greater than or equal to 0 . With the aid of the sequential minimal optimization algorithm, the optimal solution $\alpha^{*}=\left(\alpha_{1}{ }^{*}, \alpha_{2}{ }^{*}, \ldots, \alpha_{N}{ }^{*}\right)^{T}$ can be calculated, and then the optimal solutions $\omega^{*}$ and $\varepsilon^{*}$ can be obtained. And in this way, the hyperplane, namely the decision plane, is obtained. $\omega^{*}$ can be calculated using Formula (12):

$$
\omega^{*}=\sum_{i=1}^{N} \alpha_{i}^{*} l_{i} B_{i} \quad \text { s.t. } \sum_{i=1}^{N} \alpha_{i} l_{i}=0, \alpha_{i} \geq 0, i=1,2, \cdots, N
$$

There is at least one positive component $a_{j}^{*}$ that is greater than zero in $a^{*}$, so $\varepsilon^{*}$ can be calculated using Formula (13): 


$$
\varepsilon^{*}=l_{j}-\sum_{i=1}^{N} \alpha_{i}^{*} l_{i}\left(B_{i} \cdot B_{j}\right)
$$

Therefore, the desired separating hyperplane can be expressed as:

$$
\omega^{*} \cdot B+\varepsilon^{*}=0
$$

The corresponding separation decision function can be expressed by Formula 15:

$$
f(B)=\operatorname{sign}\left(\omega^{*} \cdot B+\varepsilon^{*}\right)
$$

Considering the non-linear-separability of students' book borrowing data samples, they can be mapped to a high-dimensional feature space and then the optimal solution of the linear support vector machine can be found. Suppose the mapping function from the input space to the feature space is expressed as $\phi(x)$, then the inner product between instances involved in the objective function and the classification decision function in Formulas (11) and (15) can be replaced by the kernel function defined in Formula (16) so as to complete the mapping process:

$$
K(A, B)=\langle\varphi(A), \varphi(B)\rangle=\varphi(A) \cdot \varphi(B)
$$

After the appropriate $K(A, B)$ and the penalty function $C$ which is greater than zero are selected, the optimal solution of the non-linearly-separable support vector machine can be obtained, as shown in Formula (17):

$$
\begin{gathered}
\quad \min _{\alpha} \frac{1}{2} \sum_{i=1}^{N} \sum_{j=1}^{N} \alpha_{i} \alpha_{j} l_{i} l_{j} K\left(B_{i} \cdot B_{j}\right)-\sum_{i=1}^{N} \alpha_{i} \\
\text { s.t. } \quad \sum_{i=1}^{N} \alpha_{i} l_{i}=0, \alpha_{i} \geq 0, i=1,2, \cdots, N
\end{gathered}
$$

The optimal solution of the bias term in Formula (13) can be updated as:

$$
\varepsilon^{*}=l_{j}-\sum_{i=1}^{N} \alpha_{i}^{*} l_{i} K\left(B_{i} \cdot B_{j}\right)
$$

The separation decision function can be updated as:

$$
f(B)=\operatorname{sign}\left(\sum_{i=1}^{N} \alpha_{i}^{*} l_{i} K\left(B \cdot B_{i}\right)+\varepsilon^{*}\right)
$$

In this paper, the 5-class classification problem of the perception model for students' psychological motivations for book borrowing was solved through a directed acyclic graph. Figure 5 shows the organizational structure of the support vector machine, where ten binary support vector machines were set up for the five psychological motivations, namely A learning aid, B professional research, $\mathrm{C}$ casual pleasure, D curiosity, and $\mathrm{E}$ speculation and rebellion. In the classification of the book borrowing data samples of any student, the category with the most votes would be the category of these samples. During training, the vectors corresponding to A, B; A, C; A, D; A, E; B, C; B, D; B, E; $\mathrm{C}, \mathrm{D} ; \mathrm{C}, \mathrm{E}$; and D, E were trained, from which, 10 groups of training results were obtained. In the testing stage, 10 sets of test samples were also tested, and finally the optimal results were obtained and output based on the voting results. 


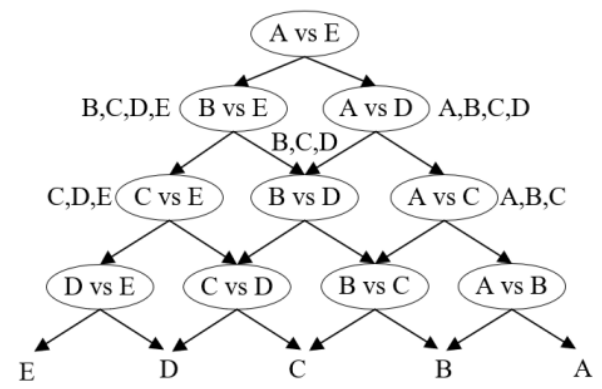

Fig. 5. Organizational structure of the support vector machine

\section{$5 \quad$ Experimental Results and Analysis}

In this paper, a perception model was constructed for students' psychological motivations for book borrowing in libraries of higher vocational colleges from the perspective of "three comprehensive education". To verify the model, experimental data sets needed to be constructed from massive historical data of students' book borrowing behaviours in higher vocational colleges. In this paper, the data used were from the library of a higher vocational college which is implementing the pilot program of "three comprehensive education", and 28 disciplines set up in this college were taken as the target disciplines for analysis of students' learning interests. Finally, more than 370,000 book borrowing records of over 7,800 students majored in 28 disciplines were obtained as data samples, which were further divided into the training set and the test set in proportion to the number of records in each discipline. Each book borrowing record contains information like the student's name, ID and major, book title, discipline category and borrowing time.

Figure 6 shows the distribution curves of students' learning interest span and discipline popularity. It can be seen that students' span of interest in different disciplines are small, indicating that, under the guidance of "three comprehensive education", most vocational college students are interested in new interdisciplinary knowledge, and their interests are relatively unified and concentrated. There are obvious differences in the popularity of different disciplines. Therefore, in future implementation of "three comprehensive education", more attention should be paid to the cross integration of disciplines, and interesting and helpful books should be recommended to students according to their interests, so as to carry forward the university spirit.

Now that the distribution of students' learning interests are known, further analysis can be made on the attributes, importance and associations of students' areas of interest and their psychological motivations for book borrowing. Figure 7 shows the changes in the clustering coefficient of students' psychological motivation types regarding book borrowing with the popularity of the discipline. The clustering coefficient here is used to characterize, for a sample classified into a certain psychological pattern by the support vector machine, the probability that its neighbours are still neighbours to each other. It is used to reflect the clustering degree of samples after classification. It can also be seen from the figure that the clustering coefficient is negatively correlated with 
the popularity of a discipline, but the feature that "the larger the number of samples of a certain class, the sparse the distribution" is not obviously shown in the model constructed in this paper. That is because, even when a discipline is popular, students' learning interests are still concentrated, and the corresponding clustering coefficient is also large.

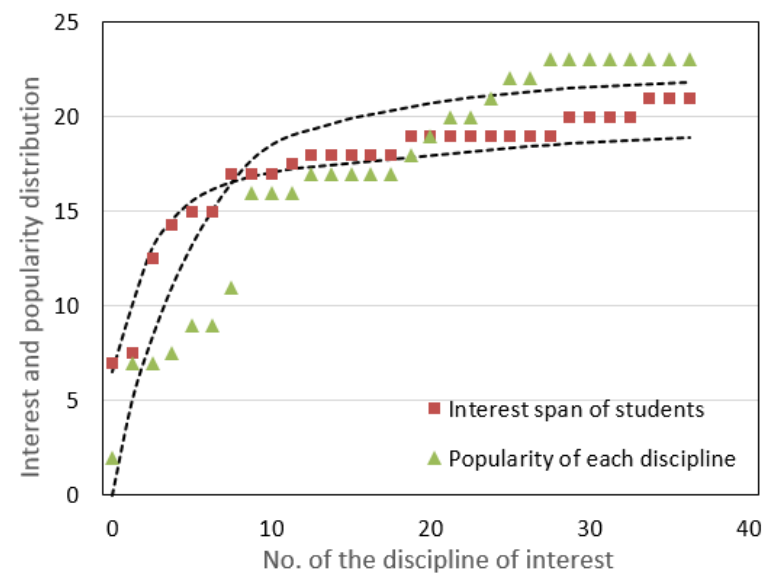

Fig. 6. Interest spans of students and popularity of disciplines

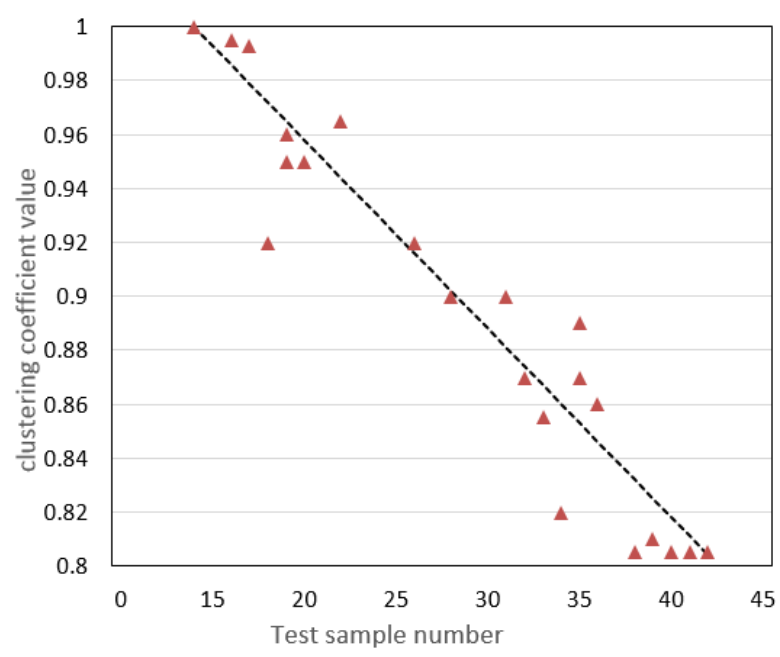

Fig. 7. Changes in the clustering coefficient with the discipline popularity

Table 1 shows the logistic regression results of the psychological pattern types of students regarding book borrowing from the perspective of "three comprehensive education". This paper conducted univariate binary logistic regression analysis on the existing static variables - learning interest span and popularity, and the dependent variables were divided into 5 groups according to the 5 types of psychological motivations 
for borrowing. From the table above, it can be seen that, for students borrowing books for learning aid and professional research, their learning interest and the popularity of the disciplines have greater impacts on their psychological motivations and patterns, and that the $\mathrm{P}$ value is smaller than 0.05 , indicating that the results have a certain statistical significance. For other three types of motivations, the $\mathrm{P}$ values are all greater than 0.05 , so learning interest and discipline popularity are not statistically significant for psychological motivations and can be ignored.

Table 1. Logistic regression results of students' psychological motivations for book borrowing

\begin{tabular}{|l|l|c|c|c|c|}
\hline \multicolumn{1}{|c}{$\begin{array}{c}\text { Type of psychological pattern } \\
\text { regarding book borrowing }\end{array}$} & \multicolumn{1}{|c}{$\begin{array}{c}\text { Popularity/interest } \\
\text { span }\end{array}$} & $\begin{array}{c}\text { Regression } \\
\text { coefficient }\end{array}$ & $\begin{array}{c}\text { Standard } \\
\text { error }\end{array}$ & $\mathbf{Z}$ value & $\mathbf{p}>|\mathbf{z}|$ \\
\hline \multirow{2}{*}{ Learning aid } & Learning interest & 0.129 & 0.093 & -0.045 & 0.046 \\
\cline { 2 - 6 } & Discipline popularity & 0.277 & 0.131 & -0.027 & 0.043 \\
\hline \multirow{2}{*}{ Professional research } & Learning interest & 0.243 & 0.051 & -0.081 & 0.034 \\
\cline { 2 - 6 } & Discipline popularity & 0.492 & 0.465 & 0.091 & 0.049 \\
\hline \multirow{2}{*}{ Casual pleasure } & Learning interest & 0.074 & 0.207 & -0.046 & 0.159 \\
\hline \multirow{2}{*}{ Curiosity } & Discipline popularity & 0.021 & 0.060 & -0.075 & 0.078 \\
\hline \multirow{2}{*}{ Speculation and rebellion } & Learning interest & 0.115 & 0.054 & 0.094 & 0.113 \\
\cline { 2 - 6 } & Discipline popularity & 0.079 & 0.468 & -0.086 & 0.184 \\
\hline & Learning interest & -0.319 & 0.202 & -0.025 & 0.279 \\
\cline { 2 - 6 } & Discipline popularity & -0.214 & 0.061 & 0.011 & 0.105 \\
\hline
\end{tabular}

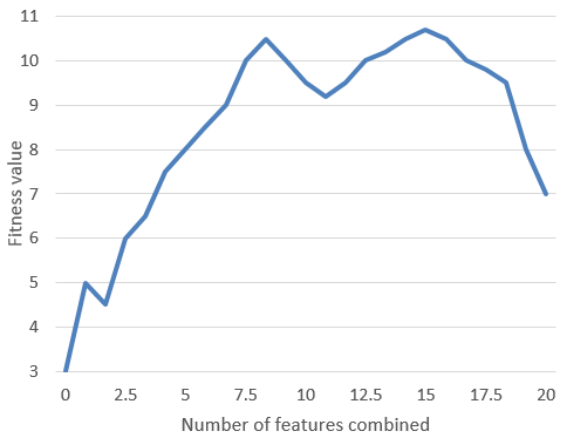

a)

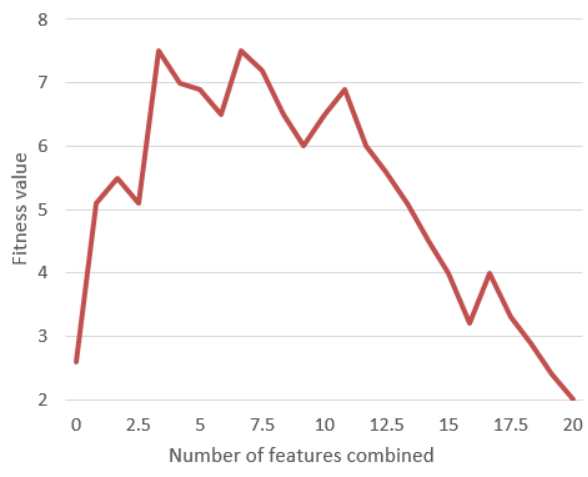

b) 


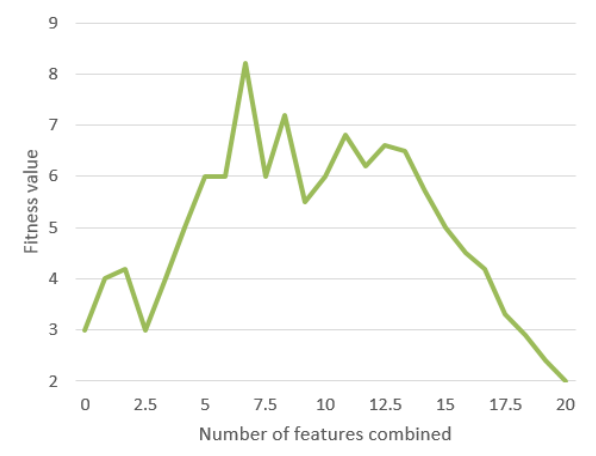

c)

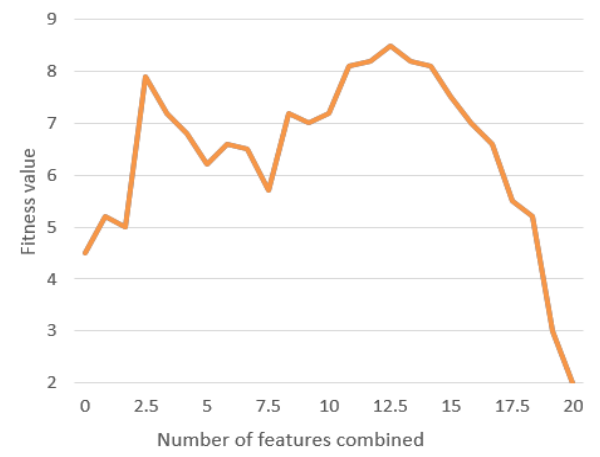

d)

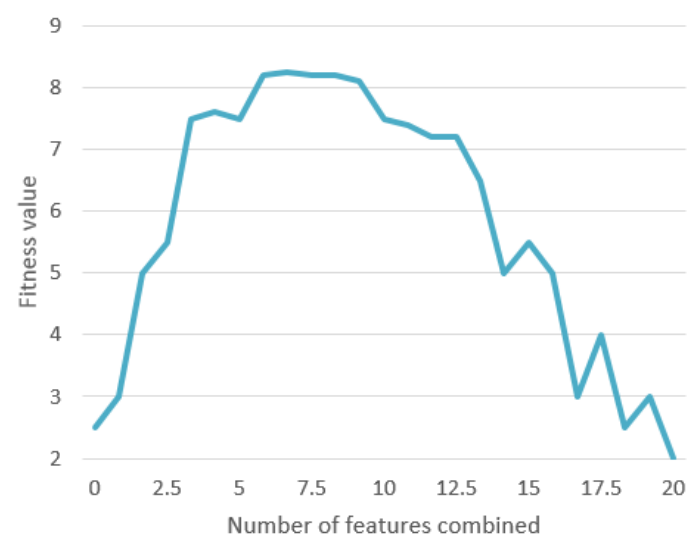

e)

Fig. 8. Effect chart of feature combinations produced by the genetic algorithm

Figure 8 is the effect chart of feature combinations produced by the genetic algorithm, where the vertical axis is the fitness value, and the horizontal axis is the number of features combined. After the types of psychological motivations for book borrowing and the 2 static variables were determined, the last step was to find out the distribution patterns of the 5 types and the associations and dependency between these types, as well as the sample classification identifiers. Figures (a), (b), (c), (d) and (e) show the different feature combinations of the 5 types. It can be seen that when there were 10, 7 , 7, 8 and 8 features combined, the effect was the best. 


\section{Conclusion}

This paper studied students' psychological motivations for book borrowing in libraries of higher vocational colleges from the perspective of "three comprehensive education". First, students' psychological motivations for book borrowing was analysed from the perspective of "three comprehensive education". The analysis process consisted of three stages - input optimization, psychological motivation and pattern perception and effect analysis of "three comprehensive education", each of which was discussed in detail. Then, for the data sample set formed from the massive borrowing information and data of students, the model input was optimized based on feature dimension compression, which effectively improved the model performance and reduced the storage cost. The experimental results verified the effect chart of the feature combinations produced by the genetic algorithm. Finally, a perception model was constructed for students' psychological motivations for book borrowing, and solved the five-class classification problem of the perception model based on the directed acyclic graph. The experimental results showed the analysis results of the learning interest span of higher vocational college students and the popularity of disciplines and the logistic regression results of their psychological motivations for book borrowing, proving the scientificity of the psychological pattern analysis method used and the effectiveness of the model proposed in this paper.

\section{$7 \quad$ References}

[1] Wang, H. (2020). Research on the integration of library e-book borrowing history data based on big data technology. In Web Intelligence, 18(2): 111-120. https://doi.org/10.3233/web$\underline{200433}$

[2] Imamoto, B., Mackinder, L. (2016). Neither beg, borrow, nor steal: Purchasing interlibrary loan requests at an academic library. Technical Services Quarterly, 33(4): 371-385. https://doi.org/10.1080/07317131.2016.1203642

[3] Devega, M. (2020, April). Implementation of ECLAT algorithm technology: Determining books borrowing pattern in university library. In IOP Conference Series: Earth and Environmental Science, 469(1): 012036. https://doi.org/10.1088/1755-1315/469/1/012036

[4] Yin, L., Yu, K. (2019). A research of readers' borrowing library books management and optimization based on big data technology. In Proceedings of the 2nd International Conference on Big Data Technologies, 87-91. https://doi.org/10.1145/3358528.3358589

[5] Maryame, N., Najima, D., Hasnae, R., Rachida, A. (2020). State of the art of deep learning applications in sentiment analysis: psychological behavior prediction. In Embedded Systems and Artificial Intelligence, 1076: 441-451. https://doi.org/10.1007/978-981-15-0947-6 42

[6] McDuff, D., Girard, J. M. (2019). Democratizing psychological insights from analysis of nonverbal behavior. In 2019 8th International Conference on Affective Computing and Intelligent Interaction (ACII), 220-226. https://doi.org/10.1109/acii.2019.8925503

[7] Zhang, M. (2012). Prediction on the Uniform Borrow and Return Service Mode of MultiCampus Libraries. Advance in Information Sciences and Service Sciences, 4(17): 251-258. https://doi.org/10.4156/aiss.vol4.issue17.28 
[8] Stratou, G., Morency, L. P. (2017). MultiSense-Context-aware nonverbal behavior analysis framework: A psychological distress use case. IEEE Transactions on Affective Computing, 8(2): 190-203. https://doi.org/10.1109/taffc.2016.2614300

[9] McKay, D., Chang, S., Smith, W., Buchanan, G. (2019). The things we talk about when we talk about browsing: An empirical typology of library browsing behavior. Journal of the Association for Information Science and Technology, 70(12): 1383-1394. https://doi.org/ 10.1002/asi.24200

[10] Dietz, M., Sippl, J., Schmidt-Vollus, R. (2019). Concept for an interoperable behavior library for virtual commissioning using PLCopenXML. In 2019 24th IEEE International Conference on Emerging Technologies and Factory Automation (ETFA), 1433-1436. https://doi.org/10.1109/etfa.2019.8869070

[11] Liu, D. D. (2017). An analysis of data citation behavior in chinese library and information domain. AGRO Food Industry Hi-Tech, 28(3): 491-495.

[12] Kadir, M. R. A., Kadir, I. K. A., Bunawan, A. A., Endin, M. Z., Zainol, Z. N. (2017). Segmentation analysis on borrowing usage behaviour of digital library services. In Proceedings of the 30th International Business Information Management Association Conference, IBIMA 2017-Vision 2020: Sustainable Economic development, Innovation Management, and Global Growth, 2017: 2920-2932.

[13] Zeng, L. M. (2015). Library collection structure improvement based on statistic analysis of borrowing - taking Fuzhou University Academy of Arts \& Craft Library as an example. Innovation in Design, Communication and Engineering - Proceedings of the 3rd International Conference on Innovation, Communication and Engineering, 847-851. https://doi.org/10.1201/b18737-180

[14] Tian, M. (2011). Application of chaotic time series prediction in forecasting of library borrowing flow. In 2011 International Conference on Internet Computing and Information Services, 557-559. https://doi.org/10.1109/icicis.2011.147

[15] Yan, F., Wang, X., Zhang, M., Deng, Z. (2010). Analysis of the structure and evolution of the co-borrowing network in Peking University library. In 2010 Seventh International Conference on Fuzzy Systems and Knowledge Discovery, 6: 2751-2755. https://doi.org/ $\underline{10.1109 / \text { fskd.2010.5569515 }}$

[16] McKay, D., Smith, W., Chang, S. (2015). Down the superhighway in a single tome: Examining the impact of book format on borrowing interactions. In Proceedings of the Annual Meeting of the Australian Special Interest Group for Computer Human Interaction, 517-525. https://doi.org/10.1145/2838739.2838766

[17] Feng, Y., Kang, M., Liu, X. X., Xu, H. Y., Gao, L., Zhou, H. M. (2015). An improved apriori algorithm based on hash table for borrowing data of library. Information Technology and Applications - Proceedings of the 2014 International Conference on Information technology and Applications, 193-198. ISBN: 978-1-138-02677-3. https://doi.org/10.1201/b18284-41

[18] Zhang, Q., Li, X., Wang, P. (2014). Association analysis of library borrowing information based on data mining technology. In Proceedings of the 9th International Symposium on Linear Drives for Industry Applications, 2: 721-728. https://doi.org/10.1007/978-3-64240630-0_92

[19] Tang, J. (2013). Study of analysis data mart in library borrowing. In Proceedings of the 2nd International Conference on Green Communications and Networks 2012 (GCN 2012), 4: 671-678. https://doi.org/10.1007/978-3-642-35440-3_86

[20] Harringer, S., Happl, B., Ozenil, M., Kast, C., Hejl, M., Wernitznig, D., (2020). Synthesis, Modification, and Biological Evaluation of a Library of Novel Water-Soluble Thiopyridone-Based Organometallic Complexes and Their Unexpected (Biological) 
Behavior. Chemistry (Weinheim an der Bergstrasse, Germany), 26(24): 5419-5433. https://doi.org/10.1002/chem.201905546

[21] Cano, L., Hein, E., Rada-Orellana, M., Ortega, C. (2018). A case study of library data management: a new method to analyze borrowing behavior. In Annual International Symposium on Information Management and Big Data, 898: 112-120. https://doi.org/ $\underline{10.1007 / 978-3-030-11680-4 \quad 12}$

\section{Author}

Rong Yan has graduated from University of Groningen in Netherlands with a Master in Science of Education. After graduation, she continues to study another Master degree, and graduated from Amsterdam International Business School with a Master in MBA. She Works in the library of Yang ling Vocational \& Technical College, Her mainly research direction is the reading promotion, management of library and subject service. She has published two articles in related journals and a textbook of English course on Water Conservancy Project. Email: zoesnow@ hotmail.com

Article submitted 2021-02-17. Resubmitted 2021-04-18. Final acceptance 2021-04-21. Final version published as submitted by the authors. 